\title{
Heartbeat: smartwatch devices for detection of atrial fibrillation
}

Smartwatch-based devices for monitoring heart rate and rhythm are increasingly popular with patients but many physicians are concerned about accuracy for detection of atrial fibrillation (AF). In a prospective multi-centre study, Rajakariar and colleagues ${ }^{1}$ compared automated smartwatch diagnosis of AF plus recording of a lead-intelligent ECG (iECG) with a conventional 12-lead ECG recorded immediately after the iECG in 200 hospitalised patients. Overall, accuracy of the smartwatch-based iECG was high at $84 \%$ with a negative predictive value $98 \%$ but positive predictive value was only $55 \%$, indicating that physician involvement is essential when the smartwatch-based device suggests AF might be present (table 1).

In the accompanying editorial, Frisch ${ }^{2}$ summarises the short history of consumer wearable heart rate and ECG devices followed by a list of selected published and in-progress studies on the use of wearable devices for detection of AF. He concludes by agreeing with the authors that 'relying on a device-provided diagnosis of $\mathrm{AF}$ to guide initiation of oral anticoagulation for stroke prophylaxis cannot be recommended at this point. Nonetheless, the future is bright and there is reason to be excited by the rapid evolution of mobile technology that we are seeing in real time. Overall, their message that although we can (and probably should) broaden our screening reach with both hardware and software, healthcare provider participation remains essential.'

Implantable cardiac defibrillator (ICD) therapy now is an essential element for prevention of sudden cardiac death in patients with heart failure (HF) and cardiac arrhythmias. Unfortunately, there are considerable geographic disparities in ICD implantation rates and the reasons for these disparities are not clear. In order to assess whether ethnicity is related to ICD implantation rates, independent of geography, Mistry and colleagues ${ }^{3}$ performed a retrospective cohort study over a 13-year period at a single tertiary centre in the UK serving a population of over 980000 people. Of the 2650 ICD

Correspondence to Professor Catherine M Otto, Division of Cardiology, University of Washington, Seattle, WA 98195, USA; cmotto@uw.edu

\begin{tabular}{|c|c|c|c|c|c|c|c|c|c|c|}
\hline KB & $\begin{array}{l}\text { Sensitivity } \\
(\%)\end{array}$ & $\begin{array}{l}\text { Specificity } \\
(\%)\end{array}$ & $\begin{array}{l}\text { PPV } \\
(\%)\end{array}$ & $\begin{array}{l}\text { NPV } \\
(\%)\end{array}$ & PLR & NLR & $\begin{array}{l}\text { Accuracy } \\
(\%)\end{array}$ & Kappa & $95 \% \mathrm{Cl}$ & $P$ value \\
\hline $\begin{array}{l}\text { Consecutive } \\
\text { unclassified } \\
\text { excluded }\end{array}$ & 94.4 & 90.7 & 72.3 & 98.4 & 10.2 & 0.06 & 91.5 & 0.76 & $\begin{array}{l}0.67 \text { to } \\
0.88\end{array}$ & $<0.001$ \\
\hline $\begin{array}{l}\text { Consecutive } \\
\text { unclassified marked } \\
\text { as incorrect }\end{array}$ & 94.4 & 81.9 & 54.8 & 98.4 & 5.2 & 0.07 & 84.3 & 0.60 & $\begin{array}{l}0.47 \text { to } \\
0.72\end{array}$ & $<0.001$ \\
\hline $\begin{array}{l}\text { KB +appropriate } \\
\text { unclassified } \\
\text { diagnosis }\end{array}$ & 95.4 & 81.9 & 59.4 & 98.5 & 5.2 & 0.06 & 84.9 & 0.71 & $\begin{array}{l}0.62 \text { to } \\
0.77\end{array}$ & $<0.001$ \\
\hline $\begin{array}{l}\text { KB +EP1 review } \\
\text { (only unclassified) }\end{array}$ & 94.4 & 91.0 & 70.8 & 98.6 & 10.5 & 0.06 & 91.7 & 0.76 & $\begin{array}{l}0.65 \text { to } \\
0.87\end{array}$ & $<0.001$ \\
\hline $\begin{array}{l}\text { KB +EP2 review } \\
\text { (only unclassified) }\end{array}$ & 94.4 & 90.4 & 69.4 & 98.6 & 9.8 & 0.06 & 91.2 & 0.74 & $\begin{array}{l}0.63 \text { to } \\
0.86\end{array}$ & $<0.001$ \\
\hline
\end{tabular}

Detailed analysis of KB accuracy for diagnosing AF with and without clinician interpretation of unclassified tracings, against cardiologist ECG diagnosis as gold standard. When the initial iECG gave an unclassified reading, a repeat iECG was taken and used as the final diagnosis. An appropriate unclassified diagnosis was determined if the tracing was due to a non-AF arhythmia. P values are derived for the kappa coefficient.

$A F$, atrial fibrillation; EP, electrophysiologist; iECG, intelligent ECG; KB, KardiaBand; NLR, negative likelihood ratio; NPV, negative predictive value; PLR, positive likelihood ratio; PPV, positive predictive value.

implants performed only $8.1 \%$ were in South Asian patients, even though South Asians comprise $15.9 \%$ of the population. Even when standardised for age, South Asians were less likely than Caucasians to receive an ICD (risk ratio $0.75,95 \% \mathrm{CI}$ 0.74 to $0.75, \mathrm{p}<0.001)$ with this difference being even greater for secondary prevention devices (table 2).

Banerjee $^{4}$ discusses the disparities in care of ethnic minorities with $\mathrm{HF}$ at every disease stage; from primary prevention to tertiary care. Banerjee concludes: 'Many of these differences are likely to be explained by differences in socioeconomic or risk factor profile (or both of these) rather than the genetic differences alone.' 'Although there are substantial gaps in descriptive and intervention research, the holistic consideration of the prevention continuum can help in addressing health disparities by ethnicity.'

The impact of comorbidities on peak cardiac troponin (cTn) levels was studied by Sundaram and colleagues ${ }^{5}$ in over

Table 2 Crude and age-standardised RRs (95\% CI) of implantable cardioverter defibrillator implantation/upgrade for South Asians compared with Caucasians from January 2006 to February 2019

\begin{tabular}{lllll}
\hline & Crude RRs & P value & Age-standardised RR & P value \\
\hline All indications & $0.430(0.374$ to 0.495$)$ & $<0.001$ & $0.747(0.741$ to 0.752$)$ & $<0.001$ \\
Primary prevention & $0.519(0.441$ to 0.611$)$ & $<0.001$ & $0.906(0.898$ to 0.915$)$ & $<0.001$ \\
Secondary prevention & $0.285(0.217$ to 0.375$)$ & $<0.001$ & $0.489(0.482$ to 0.496$)$ & $<0.001$ \\
\hline RR risk ratio. & & & &
\end{tabular}

330000 patients presenting with acute myocardial infarction (AMI). Compared with patients without each comorbidity, peak cTn levels were higher in those with chronic kidney disease but lower in those with chronic obstructive pulmonary disease, HF, previous angina or previous AMI. However, regardless of peak $\mathrm{cTn}$ levels, comorbid conditions significantly predicted 180 -day mortality (figure 1 ).

The influence of comorbidities on cTn levels is discussed further in an editorial by Neumann and Twerenbold. ${ }^{6}$ They conclude: 'As always, cardiac troponin concentrations should never be interpreted in isolation but always within the respective clinical context. While this is fairly evident for the diagnostic assessment of patients with suspected myocardial infarction, which also integrates electrocardiography, chest pain characteristics, clinical assessment and patients' history including comorbidities, it may be less clear when interpreting peak cardiac troponin concentrations. This work helps 

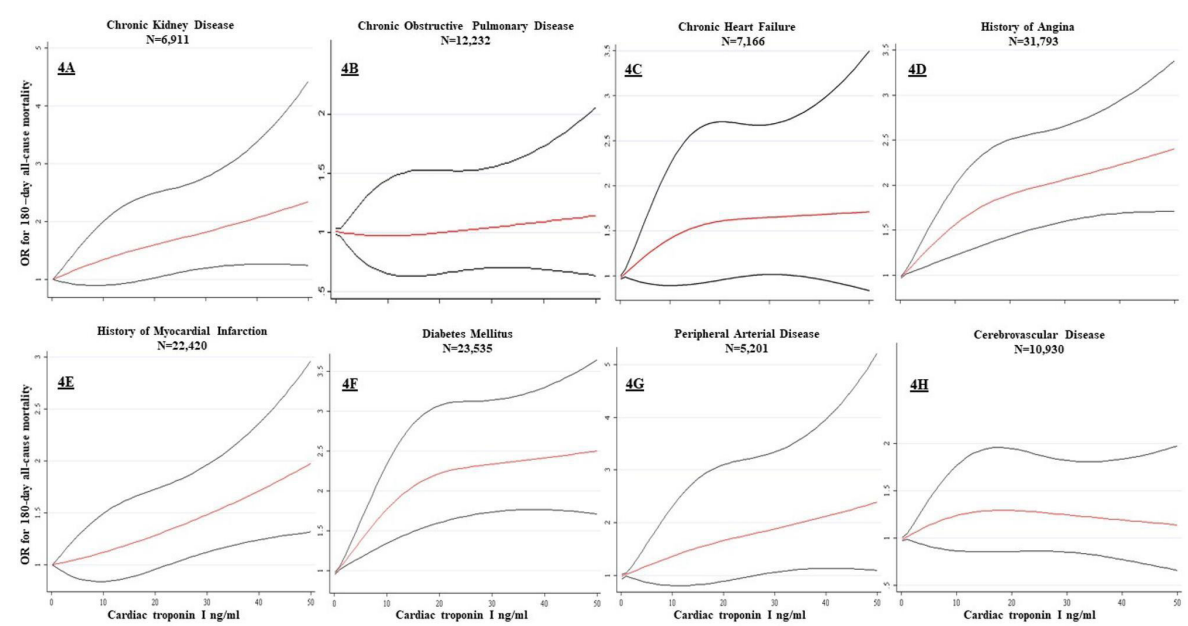

Figure $1(\mathrm{~A}-\mathrm{H})$ Association between peak cardiac troponin I and 180-day mortality in NSTEMI stratified by comorbidities (Spline Analysis*). *We used restricted cubic splines with three knots. The model was adjusted for adjusted for age, sex, smoking status, comorbidities, antiplatelet therapy, beta-blockers, statins, ACE inhibitors and revascularisation. NSTEMI, non-ST elevation myocardial infarction.

to identify and consider relevant comorbidities when using peak cardiac troponin concentrations for estimation of midterm mortality in patients with AMI.'

Also, in this issue of Heart is a narrative systematic review of shared decisionmaking (SDM) in older patients with symptomatic severe aortic stenosis (AS). ${ }^{7}$ SDM is defined as the well-defined process, which takes place when professionals and patients discuss care decisions, thereby using the best available evidence and their own preferences and personal goals' Data from 15 studies is summarised in text and tables including the six domains of SDM: preparation, goal, choice, option, decision and evaluation (figure 2). The authors identify common barriers to implementation of effective shared decision-making including inadequate "individualised formal and informal information support' and 'patients'

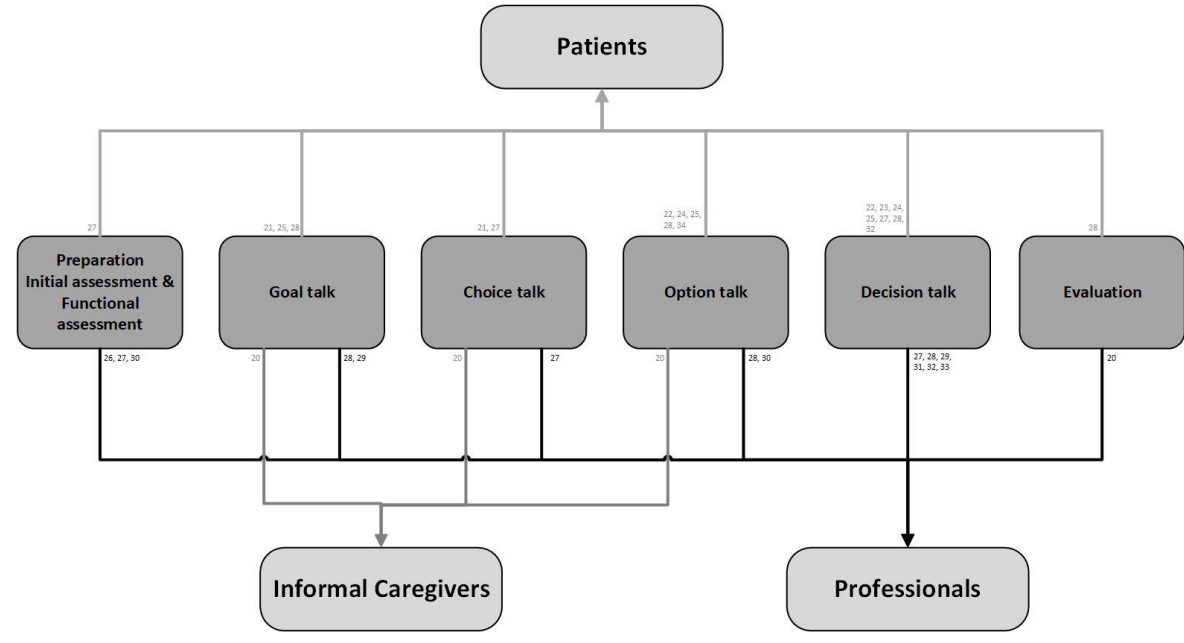

Figure 2 Shared decision for patients with symptomatic severe aortic stenosis domains in relation to perspectives in included studies. 20-34: study numbers. opportunity to use their own knowledge about their health condition and preferences for SDM'.'

Be sure to look at the Image Challenge in this issue which discusses the differential diagnosis of an elevated troponin; sometimes the correct diagnosis is reached only after a longer follow-up interval, even when coronary angiography has been performed!

\section{Contributors All authors contributed.}

Funding The authors have not declared a specific grant for this research from any funding agency in the public, commercial or not-for-profit sectors.

Competing interests None declared.

Patient and public involvement Patients and/or the public were not involved in the design, or conduct, or reporting, or dissemination plans of this research.

Patient consent for publication Not required. Provenance and peer review Commissioned; internally peer reviewed.

(c) Author(s) (or their employer(s)) 2020. No commercial re-use. See rights and permissions. Published by BMJ.

\section{Check for updates}

To cite Otto CM. Heart 2020;106:627-628.

Heart 2020;106:627-628.

doi:10.1136/heartjnl-2020-316958

\section{ORCID iD}

Catherine M Otto http://orcid.org/0000-0002-05279392

\section{REFERENCES}

1 Rajakariar K, Koshy AN, Sajeev JK, et al. Accuracy of a smartwatch based single-lead electrocardiogram device in detection of atrial fibrillation. Heart 2020;106:656-61.

2 Frisch DR. Diagnosing atrial fibrillation by mobile technology: physician decision or device provision? Heart 2020;106:629-30.

3 Mistry A, Vali Z, Sidhu B, et al. Disparity in implantable cardioverter defibrillator therapy among minority South Asians in the United Kingdom. Heart 2020;106:662-7.

4 Banerjee A. Ethnicity, heart failure and the prevention continuum: time to act. Heart 2020;106:631-3.

5 Sundaram V, Rothnie K, Bloom C, et al. Impact of comorbidities on peak troponin levels and mortality in acute myocardial infarction. Heart 2020;106:668-76.

6 Neumann JT, Twerenbold R. How do comorbidities influence troponin concentrations? Heart 2020;106:634-5.

7 van Beek-Peeters JJAM, van Noort EHM, Faes MC, et al. Shared decision making in older patients with symptomatic severe aortic stenosis: a systematic review. Heart 2020;106:647-55.

8 Bing R. Chest pain - when in doubt. Heart 2020;106:681 